\title{
Micellar Template-Mediated Nanoparticle Synthesis
}

National Cancer Institute

\section{Source}

National Cancer Institute. Micellar Template-Mediated Nanoparticle Synthesis. NCI

Thesaurus. Code C62393.

Creation of a template utilized in the preparation of certain nanoparticles. The polar heads of long chain amphipathic molecules are attached to a physical support. The nonpolar tails serve as a template for nanoparticle synthesis. 